\title{
Sex and suicide
}

\section{Gender differences in suicidal behaviour ${ }^{\dagger}$}

\author{
KEITH HAWTON
}

Qin et al's (2000, this issue) epidemiological study of risk factors for suicide in males and females in Denmark reminds us that there are important gender differences in suicidal behaviour. These reflect not only differences in aetiology, which were the primary focus of the Danish study, but also other important variations by gender in relation to risk, the nature of suicidal behaviour and its prevention and treatment.

\section{RELATIVE RISKS OF SUICIDAL BEHAVIOUR}

Rates of suicide in most countries, including Denmark, are higher in males than in females. China is one important exception, with very high rates in females, especially young women in rural areas (Cheng $\&$ Lee, 2000). In recent years, several countries have experienced an increase in suicide rates in males, particularly in the younger age groups (Cantor, 2000). In contrast, suicide rates of females have declined, especially in older women, or remained fairly stable, particularly in the young. This pattern is especially marked in the UK (Hawton, 1992), with an overall rise in male rates and a decrease in female rates (Kelly $\&$ Bunting, 1998). It suggests that causal factors and, possibly, protective factors have changed in different directions in the two genders. Social factors, especially linked to changes in gender roles, seem the most likely explanation (Hawton, 1998).

In contrast to suicides, rates of deliberate self-harm (DSH) are usually higher in females than males. The World Health Organization/EURO Multicentre Study of Suicidal Behaviour has demonstrated this pattern throughout countries in Europe, with findings from Helsinki indicating that Finland may be one exception (Schmidtke et al, 1996). There has, however, been an increase in rates of DSH in males in some

†See pp. 546-550, this issue countries. In the UK this trend has been particularly marked in young males (Hawton et al, 1997).

\section{GENDER DIFFERENCES IN THE NATURE OF SUICIDAL ACTS}

The excess rate of DSH in females, plus the stronger association between DSH and suicide in males (Hawton \& Fagg, 1988; Hawton et al, 1998), suggest that acts of DSH by females are more often based on non-suicidal motivation. In females, the appeal function of DSH, whereby DSH is used to communicate distress or to modify the behaviour and reactions of other people, seems more common. In males, DSH is more often associated with greater suicidal intent. It is interesting that in community samples, suicidal ideation is reported far more often by females than males (e.g. Paykel et al, 1974).

It is well recognised that males tend to use violent means of both suicide and DSH more often than do females. Greater suicidal intent, aggression, knowledge regarding violent means and less concern about bodily disfigurement, are all likely explanations for the excess of violent suicide in males.

\section{AETIOLOGICAL FACTORS}

As the findings of Qin et al indicate, mental illness is the predominant factor found in suicides of both genders. Their data suggest that this is an even greater risk in females. As the authors point out, however, their results are based solely on history of inpatient admission and therefore would have greatly underestimated the full contribution of psychiatric disorders. Their results do not inform us about the nature of the psychiatric illnesses from which their suicides suffered. Psychological autopsy studies clearly demonstrate that affective disorders predominate in suicides of both genders, with comorbidity of personality disorders in $40-50 \%$ and other comorbid psychiatric disorders in even more cases (e.g. Henriksson et al, 1993; Foster et al, 1997). Substance misuse disorders are, however, generally more common in male suicides (Murphy, 2000), and individuals with schizophrenia who kill themselves are also predominantly male (De Hert \& Peuskens, 2000). Eating disorders, especially anorexia nervosa, carry a high risk of suicide (Harris \& Barraclough, 1997) and most sufferers are female.

\section{SOCIO-ECONOMIC FACTORS AND MARITAL STATUS}

Unemployment, retirement, being single and sickness absence were the significant risk factors for suicide in the Danish study. While debate continues over the relative contribution of unemployment to suicidal behaviour (Platt \& Hawton, 2000), the Danish findings add to the weight of evidence that occupational factors are particularly important in suicide by males. Increased occupational instability has been proposed as one factor behind the recent increase in young male suicides, but evidence is equivocal (Hawton, 1998).

Far too little research attention has been paid to factors which protect against suicide. Qin et al identified the protective role in females of having a young child. This confirms previous research findings regarding childbearing, which indicate that pregnancy is also a time of reduced risk (Appleby, 1996). It is interesting that being a parent of a young child appeared to explain the apparent protective effect of marriage for women in the Danish study rather than married status per se, whereas in men marriage appeared to be a protective factor in its own right (or single status a risk factor). Further possible explanations proposed for the recent increase in young male suicides have been the social and economic changes that have made it more feasible for females to leave unsatisfactory relationships, which has probably exposed a greater number of vulnerable males to risk of suicidal acts (Hawton, 1998).

\section{TREATMENT}

\section{AND PREVENTION}

More females than males seek help from general practitioners for mental health problems. This probably explains why the 
apparent benefits of the educational programme in detection and treatment of depression for general practitioners on the Swedish island of Gotland were confined to females, more of whom were treated for depression and fewer of whom committed suicide (Rutz et al, 1999). While improved detection and management of psychiatric disorder is undoubtedly a key factor in the prevention of suicidal behaviour in males as well as females, there is increasing evidence, with the results of Qin et al adding to this, that alterations in socio-economic conditions are also very relevant to suicide prevention in males.

Suicide prevention strategies understandably include ensuring that clinicians and others likely to encounter people at risk have adequate risk-assessment skills. Although the predictive power of schedules to assist risk assessment is unlikely ever to be substantial (Goldney, 2000), the findings of the Danish study raise the question of whether different, if overlapping, risk-assessment schedules are required for the two genders.

Little research attention has been paid to possible gender differences in response to treatment in people at risk of suicidal acts. Clinical impression suggests that compliance of male patients is poorer than that of females. There is also some indication from treatment studies that fewer male than female DSH patients benefit from treatments that they are offered (Hawton, 1997). While this may reflect differences in overall attitudes to help, it could also result from the style of therapy that is available. Gender differences in verbal abilities and the reluctance of many males to share emotional problems may make some of the usual talking therapies less attractive to some males, at least initially. Treatment programmes that have more of a practical emphasis, perhaps focused on problem-solving, could prove more successful in engaging males at risk.

\section{CONCLUSIONS}

There are considerable gender differences in suicidal behaviour, some of which have been highlighted by the Danish study of Qin et al. These apply to the risk of suicidal

KEITH HAWTON, DM, Centre for Suicide Research, University Department of Psychiatry and Warneford Hospital, Oxford, UK. E-mail: keith.hawton@psychiatry.ox.ac.uk

(First received 18 July 2000, accepted 19 July 2000)

behaviour, and its nature, causes, prevention and treatment. We require further epidemiological studies of this kind to disentangle more of the social and economic associations with suicidal behaviour in each gender. Investigations of genetic and biological factors related to risk of suicidal behaviour are in their infancy but should be conducted from a gender perspective. Research on treatments for suicidal behaviour should investigate gender differences in response. Initiatives to develop gender-specific approaches may be indicated. Gender differences in suicidal behaviour clearly merit more research attention to generate information that can guide clinical practice and prevention strategies in ways that will prove most effective for preventing suicidal behaviour in both genders.

\section{REFERENCES}

Appleby, L. (1996) Suicidal behaviour in childbearing women. International Review of Psychiatry, 8, 107-115.

Cantor, C. H. (2000) Suicide in the Western world. In The International Handbook of Suicide and Attempted Suicide (eds K. Hawton \& K. Van Heeringen), pp. 9-28. Chichester: John Wiley \& Sons.

Cheng, A.T. A. \& Lee, C.-S. (2000) Suicide in Asia and the Far East. In The International Handbook of Suicide and Attempted Suicide (eds K. Hawton \& C. Van Heeringen), pp. 121-135. Chichester: John Wiley \& Sons.

De Hert, M. \& Peuskens, J. (2000) Psychiatric aspects of suicidal behaviour: schizophrenia. In The International Handbook of Suicide and Attempted Suicide (eds K. Hawton \& C. Van Heeringen). Chichester: John Wiley \& Sons.

Foster, T., Gillespie, K. \& McClelland, R. (1997)

Mental disorders and suicide in Northern Ireland. British Journal of Psychiatry, 170, 447-452.

Goldney, R. D. (2000) Prediction of suicide and attempted suicide. In The International Handbook of Suicide and Attempted Suicide (eds K. Hawton \& K. Van Heeringen), pp. 585-596. Chichester: John Wiley \& Sons.

Harris, E. C. \& Barraclough, B. (1997) Suicide as an outcome for mental disorders. A meta-analysis. British Journal of Psychiatry, 170, 205-228.
Hawton, K. (1992) By their own young hand. British Medical Journal, 304, 1000

- (1997) Attempted suicide. In Cognitive Behaviour Therapy: Science and Practice (eds D. Clark and C. Fairburn), pp. 285-312. Oxford: Oxford University Press.

_ (1998) Why has suicide increased in young males? Crisis, 19, 119-124.

— \& Fagg, J. (1988) Suicide, and other causes of death, following attempted suicide. British Journal of Psychiatry, 152, 359-366.

_ , _ , Simkin, S., et al (1997) Trends in deliberate self-harm in Oxford, 1985-1995. Implications for clinical services and the prevention of suicide. British Journal of Psychiatry, I7I, 556-560.

_ , Arensman, E., Wasserman, D., et al (1998) The relationship between attempted suicide and suicide rates among young people in Europe. Journal of Epidemiology and Community Health, 52, 191-194.

Henriksson, M. M., Aro, H. M., Arttunen, M. J., et al (1993) Mental disorders and comorbidity in suicide. American Journal of Psychiatry, 150, 935-940.

Kelly, S. \& Bunting, J. (1998) Trends in suicide in England and Wales, 1982-96. Population Trends, 92. 29-4l.

Murphy, G. E. (2000) Psychiatric aspects of suicidal behaviour: substance abuse. In The International Handbook of Suicide and Attempted Suicide (eds K. Hawton \& K. Van Heeringen), pp. 135-146. Chichester: John Wiley \& Sons.

Paykel, E. S., Myers, J. K., Lindenthal, J. J., et al (1974) Suicidal feelings in the general population: a prevalence study. British Journal of Psychiatry, 124 460-469.

Platt, S. \& Hawton, K. (2000) Suicidal behaviour and the labour market. In The International Handbook of Suicide and Attempted Suicide (eds K. Hawton \& K. Van Heeringen), pp. 303-378. Chichester: John Wiley \& Sons.

Qin, P., Agerbo, E., Westergård-Nielsen, N., et al (2000) Gender differences in risk factors for suicide in Denmark. British journal of Psychiatry, I77, 546-550.

Rutz, W. (1999) Improvement of care for people suffering from depression: the need for comprehensive education. International Clinical Psychopharmacology, I4, S27-33.

Schmidtke, A., Bille Brahe, U., De Leo D., et a (1996) Attempted suicide in Europe: rates, trends and sociodemographic characteristics of suicide attempters during the period 1989-1992. Results of the WHO/ EURO Multicentre Study on Parasuicide. Acta Psychiatrica Scandinavica, 93, 327-338. 